\title{
Developing organisational vision in general practice
}

\author{
Ali Al-Shehri, Ian Stanley, Paul Thomas
}

Vision is a fashionable but ill defined term in management circles. Nevertheless, it embodies a significant concept related to guiding an organisation from present realities, through opportunities and hazards, to a viable future. Until recently a typical general practice could assume a stable external environment, but now it is caught up in the uncertainties stemming from the NHS reforms. For such a practice to undertake effective strategic planning it will have to develop a vision connecting the present with aspirations for the future. While vision is usually considered to be an individual talent, it is possible to develop a collective organisational vision within a general practice, and the small size of general practices makes this relatively easy. The vision needs to be broad; it needs to be continuous; and its capacity to predict the future needs to be monitored.

\section{What's all this fuss about vision?}

In recent years NHS management colleagues have successfully transplanted from their own jargon into the everyday language of doctors a number of terms, the obvious example being "proactive." The latest contender is "vision," which crops up in the context of managing change, usually as a characteristic of individual leaders. A recent computer keyword search of management journals revealed that vision is indeed à la mode: between 1981 and 1986 the search uncovered only 916 references, but in the last four years 2200 . While the concept has been recognised from ancient times, ${ }^{1}$ this trend suggests that managers perceive vision to be increasingly important for contemporary organisations.

Certainly there is a widespread conviction that management formulas that worked in the 1980 s are proving inadequate for the challenges of the 1990s. The recurring themes are risk and instability: how do organisations chart their way through an increasingly uncertain external environment to an assured future? As a concept, vision embodies the qualities of leadership necessary to anticipate and manage the consequences, for an organisation, of change in the external world. In other words, vision precedes and makes possible effective strategic planning.

General practice, despite its much vaunted "coping with uncertainty" in consultations, ${ }^{2}$ was until recently a network of small businesses operating in a stable environment, with guaranteed demand, assured income, and traditional management style. The 1990 contract and the NHS reforms changed all that. Consumerism, the internal market, and the threat of predatory organisations competing for business in primary and community care mean that our external environment, too, has become unstable. Colleagues may welcome or rage against this new situation, but any general practice planning to survive more than five years probably needs "this vision thing."

\section{Managing without vision}

Since the formation of the NHS in the late 1940s, a typical general practice has experienced many major changes, and with hindsight most appear to have been beneficial. Almost all, however, were the result of external forces: the practice reacted to rather than initiated change. The recent NHS reforms are but the latest example of profound external change which was neither predicted nor prepared for. Only a handful of farsighted practices will have anticipated that consumerism, health promotion, and health care purchasing were to become everyday concerns of their partners and staff. For the majority failure to develop a vision of their place in what lay ahead was a defensible approach based on the assumption that their practices would cope with the future as they had always done, by reacting after the event.

However, during times of profound external change an unprepared organisation will experience a sense of alienation and disorientation. Overtaken by events, a natural reaction is to underestimate the importance of or even resist change. Isolated in this way tradition and caution flourish; mistakes are made and opportunities lost without their long term importance for the organisation being realised. Clearly some of the challenges lying ahead for general practice are momentous. For example, the key publication Integrating Primary and Secondary $\mathrm{Care}^{4}$ implies a new order of working relationships with specialists and other agencies. Each practice needs to anticipate these challenges in a well informed and imaginative way before it can devise a strategy which will enable it to participate in, and even shape, change locally. Vision is the key to effective strategic planning for general practice, as for any other organisation. On the other hand, failure to anticipate is associated with increased stress and, conceivably in the NHS internal market, decline to the point where the practice is no longer commercially or professionally viable.

\section{What is organisational vision?}

People with vision can sense signals emerging from the present which point to the nature of change. These signals may be faint, at the periphery, or equivocal. Nevertheless, visionary people bring such signals into focus, analyse, and combine them in order to make a meaningful, if theoretical, construct of the future. Such individuals exhibit exceptional vision and may become leaders on the strength of it. For an organisation, however, reliance on an individual of this kind is itself hazardous since a visionary individual in an organisation without vision is likely to be looking for another organisation. More relevant for most organisations than the visionary individual is a collective vision developed by the stakeholders in the organisation. Here, the whole is more than the sum of the parts because a broadly based, collective vision not only provides the organisation with a robust guide from the 
present to the future but also promotes common purpose and direction among those who contribute to it.

An analogy may help to show the relationship between organisational vision and strategic planning. If we wish to travel from $A$ to $B$ we can navigate from memory or use a map along with signposts, instrument readings, or external (for example, satellite) guidance. The map visualises points $A$ and $B$ along with those features of the external world which are helpful or hazardous to progress. However, in order to make progress we need to know two other things: firstly, what is travelling-rowing boat, bicycle, or juggernaut? Secondly, is there consensus that we wish to move from $\mathrm{A}$ to $\mathrm{B}$ - are there, for example, those who honestly believe we should be going to points $\mathrm{C}, \mathrm{D}$, or $\mathrm{E}$ or even some who doubt that we are currently at point $\mathrm{A}$ ?

Of course, the analogy is imperfect because, in reality, maps of or signposts to the future do not exist and therefore navigation on the basis of recall or dead reckoning is likely to prove hazardous. Vision, on the other hand, can act as an organisation's guidance system by informing the strategic planning process about three issues: $(a)$ the present realities of the organisation, $(b)$ the opportunities and hazards which may lie ahead, and $(c)$ realistic objectives within a given timescale.

Developing an organisational vision involves exploring each of these issues broadly and perceptively and thereafter synthesising the findings into a coherent picture. However, an organisational vision is a complex construct which may never be tangible; rather it is perceived within the organisation as a sense of common purpose and as a lodestone pointing the way through strategic planning to appropriate action(s).

\section{Can you get it?}

Developing an organisational vision requires key people to pool their views with the aim of making strategic planning more imaginative yet relevant and in the process becoming committed to change. The values, aspirations, and constraints of the key players and of closely related organisations must be sought and, by a process of listening, understanding, and compromise, integrated. What emerges is a collective vision which drives the organisation's planning process towards appropriate choices of action.

In a typical practice the key informants may well be partners, practice and community nurses, administrative staff, and patients plus family health services authority and district health authority colleagues concerned with local health care purchasing. For others (for example, fundholding practices) the number of informants may need to be greater, and people from the regional health authority, social services and the voluntary sector, community pharmacists, schools, etc, might all have a role. In either case, the organisational vision is incomplete without encompassing likely developments in the NHS (for example, the local community trust's strategic plan; proposed outreach services from a local hospital trust) and in the private sector. Then there are issues like Health of the Nation, the future shape of the NHS intermediate tier, and implications of Caring for People; and there are many more.

A vision unique to each practice comes about through this complex interaction being perceived from the many different perspectives of its personnel and closely related organisations. Coupled with this must come the resources, including the skills and motivation, to identify and pull together common themes and trends. This is eminently feasible in a small organisa- tion like general practice; it does, however, involve a number of steps, each of which is important.

\section{How do you get it?}

The first step is to have available the key informants -a mix of people each with a stake in the future of the organisation. Next the practice will need to find methods for everyone to articulate their perspective so that it is understood and valued by others. The range of methods includes the following.

Vision workshop-Here people imagine themselves into the future and ask what they would like the world to look like.

Brainstorming-Here relevant ideas are captured on a white board or flip chart and later put into priority order or organised under headings.

Buzz groups-Small groups as subsections of the larger group look at some tightly focused part of the whole area under discussion; in a feedback session this then informs the whole.

Chaired meeting-Here the chairperson directs proceedings, inviting comments from people, clarifies, and feeds back and ensures that minutes are kept and points of agreement identified.

Swot analysis (strengths, weaknesses, opportunities, and threats) is a popular form of structured brainstorming with particular relevance to strategic planning.

Domainal mapping-Here the effects of change on individual disciplines in the primary health care team can be discussed and made clear. ${ }^{5}$ It is effectively a multisectoral Swot analysis.

Briefing papers-One person writes down an analysis of a given situation revealing the possible outcomes as he or she sees it. Each individual in the organisation then uses this as a starting point for thought and amends and changes things to eflect his or her personal perspective.

Facilitated discussion-Here a neutral outsider or someone allocated the role helps the development of discussion inside an existing group.

These methods help people to see beyond the pressing priorities of the moment to imagine, understand, and influence the future. At the same time they promote teamwork and, by increasing the stake of individuals in the organisation, corporateness. Identifying and exploring relevant issues are not enough, however. The organisational vision emerges only at the final step, a balanced and perceptive integration of the issues into a whole. A trusted figure within the practice will need to sift, organise, and reconcile conflicts within the evidence and ultimately synthesise the organisational vision. While management must ensure that this happens, it is the guardian rather than the owner; so defined, the vision belongs to everyone in the organisation.

\section{Where does the organisational vision reside?}

When the initial synthesis accurately reflects the broad basis of the evidence everyone in the practice should feel a sense of ownership. However, the curren vision needs to be constantly reviewed against the realities of the present and new signals about the future. Theoretically, at least, the vision is not only intangible; it is never fixed. This dilemma is a huge (perhaps insoluble) problem for large organisations but given the scale of most general practices at least two approaches are feasible. Firstly, a two way communication policy can be established which attempts both to share the current vision regularly and at the same time receive signals which suggest that it may need to be amended. This sort of regular face to face briefing is, in our view, an essential element of good management 
practice. Secondly, attempts can be made to capture current thinking in documentary form. Annual business plans and longer term strategic direction statements are tangible expressions of the organisation's vision.

These manifestations of the organisational vision are complementary rather than interchangeable approaches. Too great a reliance on documents runs the risk of them being seen as "tablets of stone" and may stifle imagination. On the other hand, alone informal communication and "networking" can result in wasted effort through lack of coherence: the vision is overwhelmed by indiscriminate and uncoordinated brainstorming. Each practice will need to strike a balance between these contrasting approaches which suits its size, personnel, and management style.

\section{How do you know if you've still got it?}

We have suggested that the practice vision needs to be broadly defined and regularly refreshed. This can come about only if individuals invest time and effort in the process. To justify and sustain this investment the quality of the resulting vision needs to be monitored. So how does an organisation know if its vision continues to be sound? Surprisingly, the answer is straightforward: if vision guides the organisation's planning, then as the future unfolds there are numerous reference points against which the meaningfulness (strictly, the predictive validity) of the vision can be checked and appropriate adjustments made. Without careful monitoring of this kind the organisational vision will sooner or later fail, perhaps catastrophically. Failure will be evident in two ways: external change will hit the practice with little or no warning; and rigorous organisational audit will reveal that significant objectives are not being achieved.

The next time you get angry about a "bolt from the blue" in the form of a decision by the Department of Health, General Medical Services Committee, family health services authority, regional health authority, etc, ask yourself: Should I have anticipated this? If when judged honestly the answer is yes, then something is wrong with your organisational vision. If the answer is no, take stock of any implications and build into your strategic plan sufficient resilience to cope with the (very) occasional surprise.

1 Holy Bible. Genesis xxxvii, 5-11, xl-xli.

2 Stephens GG. The intellectual basis of family practice. $f$ Fam Pract 1975;2:423 3 McCormick J. The vision thing: try it, you'll like it. Business Month 1990;135 (May):66-9.

4 NHS Management Executive. Integrating primary and secondary health care. London: NHSME, 1991.

5 Spiegal N, Murphy E, Kinmonth AL, Ross F, Bain J, Coates R. Managing change in general practice: a step by step guide. $B M \mathcal{F}$ 1992;304:231-4.

(Accepted 17 May 1993)
Department of General Practice, United Medical and Dental Schools of Guy's and St Thomas's Hospitals, London SE11 6SP

Leone Ridsdale, senior lecturer in general practice Sundhiya Mandalia, assistant statistician in public health medicine

Hita Vora, research assistant in public health medicine

Department of General Practice, University of Leeds, Clinical Sciences Building, St James's Hospital, Leeds LS9 7TF Alison Evans, lecturer in general practice

Old School Surgery, Pontyclun, Mid Glamorgan, Wales William Jerrett, general practitioner

The Surgery, Leiston, Suffolk IP16 4ES Kay Osler, general practitioner

Correspondence to: Dr Ridsdale.

BMF 1993;307:103-6

\title{
Patients with fatigue in general practice: a prospective study
}

\author{
Leone Ridsdale, Alison Evans, William Jerrett, Sundhiya Mandalia, Kay Osler, Hita Vora
}

\section{Abstract}

Objective-To describe the characteristics of patients attending their general practitioners and complaining of fatigue or being "tired all the time."

Design-Prospective study of cohort aged 16 years and older with follow up at two weeks and by questionnaires at two and six months.

Subjects-220 patients (164 women) with mean age 43 years and an age-sex matched comparison group.

Settings-Doctors and patients in four practices in Lancashire, Mid Glamorgan, Suffolk, and Surrey.

Main outcome measures-General clinical data, results from standard group of laboratory tests, fatigue questionnaire, and 12 item general health questionnaire.

Results-Over twice as many patients with fatigue had high scores on the health questionnaire compared with the comparison group $(156(75 \%) v 69$ $(34 \%))$. Results of laboratory tests were abnormal and contributed to the diagnosis in 19 patients. 59 out of 102 patients who responded had high fatigue scores six months later. Patients with persistent fatigue were more likely to have a history of anxiety or depression and to have had fatigue for more than three months on entry to the study.

Conclusions-Women are particularly at risk of fatigue. The outcome is better if patients have had symptoms for three months or less or there is no history of emotional illness.

\section{Introduction}

Fatigue is a common subjective experience. Hannay reported on responses to interviews at home with patients from one practice and found that nearly a quarter of responders felt more tired or run down than usual. ${ }^{1}$ After respiratory symptoms this was the most common physical symptom described. Only a small proportion of those who experience fatigue as a problem come to the doctor. Morrell and Wale linked symptoms reported in women's diaries to their consultations in one practice and found a ratio of 400 episodes recorded to one consultation for fatigue. ${ }^{2}$

Fatigue may be the main complaint or a "supporting" symptom. Jerrett found about 75 per 1000 registered patients attended with fatigue as a presenting or supporting symptom in one year. ${ }^{3}$ Morrell found about 13 per 1000 registered patients presented with fatigue as their main complaint, and fewer than $2 \%$ were referred to secondary care. ${ }^{4}$ General practitioners can probably gain no useful information from research on fatigued patients in secondary or tertiary care.

During medical training clinical teaching is often focused on problems in which the diagnoses can be defined and there is some evidence from research to guide management. General practitioners often see patients with tiredness, but there is little scientific evidence from research done in primary care. ${ }^{5}$ In this context practitioners experience uncertainty, which may impair their confidence and relationships with patients.

We aimed to describe the characteristics of patients who consulted their general practitioners with a main complaint of fatigue or being tired all the time; compare their symptoms of fatigue reported on questionnaires with those reported by a comparison group matched for age and sex from the practice lists; and compare their symptoms of psychological distress reported on questionnaires with those of the comparison group. We also analysed the results of standard laboratory tests; measured the change in symptoms at intervals over a six month follow up period; and determined the characteristics on entry which predicted patients' fatigue symptoms six months later. 